\title{
Angka kejadian ambliopia pada usia sekolah di SD Negeri 6 Manado
}

\author{
${ }^{1}$ Fikryah E. Saputri \\ ${ }^{2}$ Yamin Tongku \\ ${ }^{2}$ Herny Poluan
}

\author{
${ }^{1}$ Kandidat Skripsi Fakultas Kedokteran Universitas Sam Ratulangi Manado \\ ${ }^{2}$ Bagian Ilmu Mata Fakultas Kedokteran Universitas Sam Ratulangi Manado \\ Email: fikryahekasaputri@gmail.com
}

\begin{abstract}
Amblyopia is the reduced of visual acuity in one or both eyes despite had been corrected with spectacles without any structural abnormalities of the eye and the rear sight path. Amblyopia occurs in about 2-3\% of the population, but lacking of concern will lead to detrimental life. This study was aimed to obtain the prevalence of amblyopia in elementary school students of SD Negeri 6 Manado. This was a descriptive study with a cross-sectional design. Samples were 317 elementary school students aged 6-12 years old. Data were obtained by using auto refractometer and Snellen chart as well as pinhole test to assess the eyes disorders. The results showed that of all respondents there were 7 students $(2 \%)$ with amblyopia. Based on the age of the incidence of amblyopia there were 3 students of 8 years old $(43 \%)$ and 1 student each in the age of 7 years, 9 years, 11 years, and 12 years $(14.25 \%)$. Amblyopia was found in $4(57 \%)$ female students and $3(43 \%)$ male students. Further studies are needed with a larger coverage area to obtain the prevalence of amblyopia more accurately.
\end{abstract}

Keywords: amblyopia, prevalence, school-age children

\begin{abstract}
Abstrak: Ambliopia adalah berkurangnya ketajaman penglihatan pada satu atau kedua mata walaupun sudah dengan koreksi kacamata terbaik tanpa kelainan struktur pada mata maupun lintasan penglihatan bagian belakang. Ambliopia merupakan masalah dalam penglihatan pada $2-3 \%$ populasi, tapi bila dibiarkan akan sangat merugikan kehidupan penderita. Penelitian ini bertujuan untuk mengetahui angka kejadian ambliopia di SD Negeri 6 Manado. Jenis penelitian ialah deskriptif dan pengumpulan data dilakukan secara potong lintang. Sampel ialah 317 siswa berusia sekolah 6-12 tahun. Pengambilan data dengan menilai kelainan refraksi menggunakan auto refrraktometer dan Snellen chart serta pinhole untuk menilai kelainan pada mata. Hasil penelitian mendapatkan dari seluruh responden didapatkan 7 anak (2\%) mengalami ambliopia. Berdasarkan usia, angka kejadian ambliopia pada usia 8 tahun sebanyak 3 anak (43\%) dan pada usia 7 tahun, 9 tahun, 11 tahun serta 12 tahun sebanyak 1 anak (14,25\%). Berdasarkan jenis kelamin angka kejadian ambliopia pada perempuan yaitu 4 anak (57\%), sedangkan laki-laki sebanyak 3 anak (43\%). Studi lanjut diperlukan dengan cakupan wilayah dan jumlah sampel yang lebih luas sehingga mendapatkan nilai prevalensi ambliopia yzng lebih akurat.
\end{abstract}

Kata kunci: ambliopia, angka kejadian, anak usia sekolah

Penglihatan merupakan salah satu indra penting bagi manusia yang berfungsi sebagai indra penglihatan yang juga membantu dalam perkembangan identitas diri, kepandaian dan keterampilan. Proses penglihatan mengalami perkembangan dimulai sejak bayi lahir. Terdapat beberapa periode kritis untuk mencapai tingkat yang matang. Periode kritis pertama yang paling menentukan ialah 6 bulan pertama 
kehidupan, kemudian sampai 2 tahun, berikutnya sampai 5 tahun. Sesudah 5 tahun masih ada perkembangan, tetapi sudah tidak begitu pesat lagi sampai usia 9 tahun. ${ }^{1,2}$ Pada perkembangan penglihatan yang tidak normal dapat mengakibatkan pengurangan ketajaman penglihatan.

Ambliopia merupakan penyebab terbanyak penurunan ketajaman penglihatan pada anak, remaja, dan dewasa muda. Anak merupakan prioritas dalam VISION 2020, yang WHO menggagas untuk dapat mencegah gangguan ketajaman penglihatan dibanding gangguan lain yang memerlukan deteksi dini misalnya katarak kongenital, amblyopia merupakan gangguan yang diderita orang awam dan dalam laporan pengelolaan menempati proporsi yang tinggi dalam hubungan antara dokter mata dengan anak-anak. ${ }^{3,4,5}$

Ambliopia dikenal juga dengan istilah "mata malas" (lazy eye), adalah berkurangnya ketajaman penglihatan pada satu atau kedua mata walaupun sudah dengan koreksi kacamata terbaik tanpa ditemukan kelainan struktur pada mata maupun lintasan penglihatan bagian belakang. Ambliopia disebabkan karena pengalaman penglihatan yang abnormal dari salah satu hal berikut : strabismus; anisometropia atau kelainan refraksi kedua mata yang tinggi (isoametropia) atau kekurangan stimulus. ${ }^{6}$

Walauppun ambliopia hanya mengenai 2-3\% populasi, tapi bila dibiarkan akan sangat merugikan nantinya bagi kehidupan penderita. ${ }^{7}$ Prevalensi ambliopia yang terdeteksi pada anak-anak diperkirakan antara 0,2-5,4\% dan pada dewasa antara 0,35-3,6\%. Di Eropa, prevalensi ambliopia pada anak berkisar 1-2,5\%. Prevalensi ambliopia lebih tinggi terjadi pada negara berkembang. Di Indonesia sendiri didapatkan prevalensi ambliopia pada siswa kelas 1 sekolah dasar (SD) di Kotamadya Bandung pada tahun 1989 sebesar 1,56\%. Penelitian mengenai ambliopia pada 2268 siswa SD usia 7-13 tahun di Yogyakarta pada tahun 2008 mendapatkan hasil amblyopia $1,5 \% .^{6}$

Ambliopia tidak dapat sembuh dengan sendirinya dan bila tidak diterapi dapat menyebabkan gangguan penglihatan permanen. Jika nantinya pada mata yang baik itu timbul suatu penyakit atau trauma, maka penderita akan bergantung pada penglihatan buruk dari mata yang ambliopia; oleh karena itu ambliopia harus ditatalaksana secepat mungkin. ${ }^{7}$ Hampir seluruh ambliopia dapat dicegah dan bersifat reversibel dengan deteksi dini dan intervensi yang tepat. ${ }^{7,8}$ Anak dengan ambliopia atau yang beresiko ambliopia hendaknya dapat diidentifikasi pada usia dini, dimana prognosis keberhasilan terapi akan lebih baik. ${ }^{1}$

Penelitian ini bertujuan untuk melakukan deteksi dini dan publikasi informasi mengenai angka kejadian ambliopia pada anaak usia sekolah SDN 6 Manado Sulawesi Utara.

\section{METODE PENELITIAN}

Jenis penelitian ini ialah deskriptif dengan pengumpulan data secara potong lintang. Penelitian ini dilakukan pada bulan September - Oktober 2016 dengan lokasi penelitian di SD Negeri 6 Manado. Populasi dalam penelitian ini ialah semua pelajar yang belajar di SD Negeri 6 Manado yang mengalami ambliopia. Sampel dalam penelitian ini ialah siswasiswa kelas 1 - 6 SD Negeri 6 Manado yang mengalami ambliopia dan memenuhi kriteria inklusi. Pengambilan sampel dalam penelitian ini dilakukan secara total sampling.

Kriteria inklusif penelitian yaitu siswasiswi kelas 1 - 6 SD Negeri 6 Manado yang mengalami ambliopia dengan rentang usia 6-12 tahun serta bersedia terlibat dalam penelitian ini dengan menandatangani Informed Consent. Kriteria eksklusi yaitu siswa-siswi kelas 1-6 SDN 6 Manado yang tidak mengalami ambliopia dengan rentang usia 6 - 12 tahun dan yang tidak bersedia terlibat dalam penelitian ini atau tidak hadir saat pengambilan data, misalnya sedang sakit atau izin.Dalam penelitian ini digunakan variablel antara lain usia, jenis kelamin, dan jenis ambliopia.

Data primer dikumpulkan dengan melakukan wawancara menggunakan 
kuesioner dan pemeriksaan visus terhadap sampel penelitian.

Penelitian ini merupakan penelitian deskriptif kategorik. Semua perhitungan statistik dilakukan secara manual untuk mendapatkan hasil lebih akurat. Data yang telah diolah akan disajikan dalam bentuk tekstular dan tabular. Data yang telah di peroleh dan diolah secara statistik menggunakan analisis univariat.

\section{HASIL PENELITIAN}

Penelitian ini dilakukan pada siswasiswi kelas 1-6 SD dengan kisaran umur 612 tahun yang memenuhi kriteria inklusi yaitu sebanyak 317 siswa (Tabel 1).

Tabel 1. Distribusi karakteristik siswa-siswi SD Negeri 6 Manado

\begin{tabular}{cccc}
\hline Karakteristik & Klasifikasi & (n) & \% \\
\hline Usia & 6 Tahun & 31 & 10 \\
& 7 Tahun & 64 & 20 \\
& 8 Tahun & 49 & 15 \\
& 9 Tahun & 34 & 11 \\
& 10 Tahun & 53 & 17 \\
& 11 Tahun & 57 & 18 \\
& 12 Tahun & 29 & 9 \\
Jenis Kelamin & Laki- laki & 185 & 42 \\
& Perempuan & 132 & 58 \\
Jumlah & & 317 & 100 \\
\hline
\end{tabular}

Dari hasil penelitian didapatkan bahwa sebagian besar siswa-siswi (310 anak) tidak menderita ambliopia yaitu sekitar $98 \%$ dan hanya beberapa siswa (7 anak) menderita ambliopia 2\% (Tabel 2).

Tabel 2. Distribusi frekuensi responden yang mengalami ambliopia pada siswa-siswi SD Negeri 6 Manado berdasarkan usia

\begin{tabular}{ccc}
\hline Usia & (n) & $\%$ \\
6 Tahun & 0 & 0 \\
7 Tahun & 1 & 14,25 \\
8 Tahun & 3 & 43 \\
9 Tahun & 1 & 14,25 \\
10 Tahun & 0 & 0 \\
11 Tahun & 1 & 14,25 \\
12 Tahun & 1 & 14,25 \\
Jumlah & 8 & 100 \\
\hline
\end{tabular}

Dalam penelitian ini, prevalensi responden berjenis kelamin perempuan yang menderita ambliopia lebih banyak dibandingkan laki-laki (Tabel 2).

\section{BAHASAN}

Jenis penelitian ini ialah deskriptif dengan desain potong lintang yang dilaksanakan di SD Negeri Manado kelas 1-6. Jumlah murid sebanyak 476, dan yang masuk dalam sampel penelitian sebanyak 317. Berdasarkan data yang terkumpul usia murid 6 tahun berjumlah 31 orang (10\%), umur 7 tahun berjumlah 64 orang (20\%), umur 8 tahun berjumlah 49 orang (15\%), umur 9 tahun berjumlah 34 orang (11\%), umur 10 tahun berjumlah 53 orang (17\%), umur 11 tahun berjumlah 57 orang (18\%), dan umur 12 tahun berjumlah 29 orang (9\%). Persentase anak yang berjenis kelamin laki-laki berjumlah 185 orang (42\%) lebih tinggi dibanding anak-anak yang berjenis kelamin perempuan 132 orang $(58 \%)$.

Berdasarkan hasil penelitian pada 317 responden didapatkan bahwa terdapat 7 murid $(2 \%)$ yang terdiagnosis menderita ambliopia. Hasil ini sesuai dengan penelitian yang dilakukan oleh Shrestha et al. ${ }^{10}$ terhadap 2.236 anak sekolah di Jhapa, Nepal dan mendapatkan prevalensi ambliopia sebesar 2,01\%. Penelitian lainnya juga menunjukkan persentasi ambliopia yang hampir sama seperti Suhardjo dan Sasongko di Yogyakarta pada 2.268 siswa SD usia 7-13 tahun mendapatkan prevalensi ambliopia di daerah perkotaan sebesar $1,93 \%{ }^{11}$ Rajavi et al. ${ }^{13}$ melakukan penelitian di Tehran, Iran pada siswa SD usia 7-12 tahun sebanyak 2.410 responden dan didapatkan prevalensi ambliopia sebesar 2,3\%. ${ }^{13}$ Prevalensi ambliopia di Amerika Serikat sulit untuk ditaksir dan berbeda pada tiap acuan pustaka berkisar antara 1-3,5\%. Hampir seluruh data mengatakan sekitar $2 \%$ dari

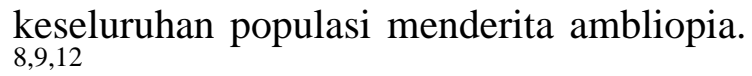

Berdasarkan hasil penelitian pada Tabel 2, dapat dilihat bahwa distribusi frekuensi ambliopia berdasarkan usia 
responden paling banyak pada siswa-siswi yang berusia 8 tahun yaitu sebanyak 3 orang $(50 \%)$, dan jumlah responden yang mengalami ambliopia paling sedikit berusia 7 tahun, 9 tahun, 11 tahun, dan 12 tahun yaitu sebanyak 1 orang $(14,25 \%)$. Dalam penelitian ini jumlah responden yang mengalami ambliopia usia 6 tahun dan 10 tahun tidak ditemukan. Usia yang diketahui berisiko tinggi terjadinya ambliopia pada masa kritis dalam perkembangan ketajaman penglihatan seseorang yatu sejak usia beberapa bulan hingga 7-8 tahun. ${ }^{8}$

Berdasarkan hasil penelitian dapat dilihat bahwa distribusi frekuensi ambliopia berdasarkan jenis kelamin yang paling banyak didapatkan pada perempuan sebanyak 4 orang (57\%), sedangkan lakilaki sebanyak 3 orang (43\%). Meskipun secara umum prevalensi ambliopia tidak dipengaruhi oleh perbedaan jenis kelamin, namun hasil penelitian ini sama dengan hasil penelitian yang didapat sebelumnya oleh Faghihi et al. ${ }^{14}$ menyatakan frekuensi pada perempuan lebih tinggi dibanding laki-laki. ${ }^{14}$ Hal tersebut berbeda dengan hasil penelitian yang dilakukan oleh Yekta et al. ${ }^{15}$ di Shiraz, Iran yang menunjukkan prevalensi ambliopia lebih tinggi didapatkan pada laki-laki dibandingkan perempuan.

\section{SIMPULAN}

Berdasarkan hasil penelitian secara deskriptif retrospektif di SD Negeri 6 Manado dapat disimpulkan bahwa angka kejadian ambliopia di SD Negeri 6 Manado dari 317 responden sebesar 2\%, dan tersering pada usia 8 tahun dan jenis kelamin perempuan,

\section{SARAN}

1. Untuk peneliti yang akan datang yang ingin melakukan penelitian tentang ambliopia, agar dapat melakukan penelitian lanjutan dengan cakupan wilayah dan jumlah sampel yang lebih luas sehingga didapatkan nilai prevalensi ambliopia nasional.
2. Perlu penelitian lebih lanjut dan menyeluruh terhadap faktor resiko ambliopia selain dari kelainan refraksi

3. Bagi Bagian Ilmu Kesehatan Mata BLU RSU Prof. DR. R. D. Kandou Manado, perlu diadakan penyuluhan tentang ambliopia, yaitu mengenai bahaya ambliopia pada anak yang tidak terdeteksi dan terkoreksi sejak dini.

4. Bagi masyarakat khususunya para orangtua dan para guru di sekolah agar dapat memperhatikan perilaku aktivitas melihat pada anak dan anak didiknya agar apabila terdapat kelainan dapat segera dikoreksi.

\section{DAFTAR PUSTAKA}

1. Sidarta IH. Ilmu Penyakit Mata (3rd ed). Jakarta: Balai Penerbit FKUI, 2006.

2. Press L, Coats D. Amblyopia. Harley Pediatric Ophthalmology (5th ed). Philadelphia, 2004.

3. Gunawan W. Astigmatisma miop simplek yang mengalami ambliopia pada anak sekolah dasar di Yogyakarta. Berita Kedokteran Masyarakat. 2006;22: 135139.

4. Simons K. Preschool vision screening: rationale, methodology and outcome, Surv Ophthalmol. 1996;41:3-30.

5. Rahi JS, Dezateux C. Improving the detection of childhood visual problem and eye disorder. Lancet. 2002; 359:1083-1084

6. Widadi KW, Suhardjo, Hartono. Ambylopia among junior high school students. Ophthalmol Ina. 2015;41(3): 283-288.

7. Lee J, BaileyG, Thompson V. Amblyopia (Lazy eye). Available from: http://www.allaboutvision.com/conditio ns/amblyopia.htm

8. Yen KG. Amblyopia. Available from: http://www.emedicine.com/OPH/topic 316.htm

9. Amblyopia in common eye conditions disorders and disease. Available from: http://www.middleseweye.com/eye_co nditions.htm

10. Shrestha GS, Sujakhu D, Joshi P. 2011. Refractive error among school children in Jhapa, Nepal. J Opthalmol. 2011;4(2):49-55

11. Suhardjo, Sasongko MB, Anugrahsari S. 
The Yogyakarta Eye Study: A pilot assessment of astigmatism and amblyopia in elementary school children. Clinical and Experimental Ophthalmology. $\quad 2008 ; 36$ (SuppI): A278-A281.

12. Leske MC, Hawkins BS. Screening: Relationship to diagnosis and therapy in Duane's Clinical Ophthalmology; Chapter 54; Volume 5 (Revised edition). Lippincott Williams \& Wilkins, 2004.
13. Vaughan DG, Asbury T, Eva PR. Oftalmologi umum. Jakarta: Widya Medika, 2002; p. 243-4.

14. Faghihi M, Ostadimoghaddam H, Yekta A A. Amblyopia and strabismus in Iranian school children, Mashhad. Strabismus. 2011;19:147-52.

15. Yekta A, Fotouhi A, Hashemi H. The prevalence of anisometropia, ambliopia and strabismus in school children of Shiraz, Iran. 2010;18(3): 104-10. 